\title{
Medical applications of industrial safety science
}

\section{T W van der Schaaf}

\section{Healthcare workers could learn much from the engineering and civil aviation industries about safety management.}

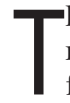
he medical community is becoming more open to learning safety lessons from other domains, but it should remain aware of the sometimes differing tasks and contexts. These same differences could also challenge experienced safety researchers to cross the boundary from industry and transportation into health care in order to contribute to the understanding, measurement, and enhancement of "patient safety".

Over the last few decades safety science has developed rapidly thanks to the (frequently disaster related) "challenges" in the areas of industry (chemical and nuclear) and transportation (civil aviation) where failures could simply not be tolerated any longer by the public and government. These domains have risked their "licence to operate" on several occasions and concluded that their control of processes had to change at the system level. This sense of urgency is not yet widespread in the medical profession nor among patients. So how can the brave storm troopers from a limited number of medical sectors get the most out of the available experiences? This editorial attempts to summarise the main lessons available to healthcare workers.

\section{PERSPECTIVES AND ATTITUDES}

Probably the most valuable lesson that industry has learned is that safety management is more than buying and applying a set of tools and techniques: without the proper changes in culture, perspective, and attitude toward errors, failures and their causes, introducing tools with the hope of a "quick fix" will largely miss the point. Safety must be recognised as a systems problem ${ }^{1}$ instead of the present "blaming and shaming" of individuals working at the sharp end. The focus of incident investigations must therefore be on the latent factors ${ }^{2}$ and not just on the immediate precursors and local triggers. These underlying factors are also present in "near misses" to wait for an actual injury to a patient to discover the root causes and to address them proactively. Early discovery is much more likely when the risk assessment of a medical process and the countermeasures are based on a large database of incidents, instead of the all too frequent ad hoc "firefighting" of symptoms after each and every (usually major) mishap. This will require a bold change in the attitudes of healthcare managers and regulators alike. The role of staff members must also be recognised-not just as the cause of adverse events but also as the strongest safety link in health care. ${ }^{3}$ Many imperfections in the organisational and technical context in which health care works are detected, understood, and corrected before patients are harmed. The implicit notion of the duality of the human component in health care allows us to address adverse events on two fronts: by preventing initial errors and failures, and by building into the system timely and effective recovery opportunities. Eventually, such perspectives and attitudes will consolidate into a proper safety culture.

\section{MODELS, TOOLS AND \\ TECHNIQUES}

Industry has operationalised the safety culture and attitudes in a number of widely used models, tools, and techniques which can be subdivided into prospective, retrospective, and organisational learning centres. Prospective approaches (aimed at predicting risk factors) are relatively new in health care. Failure mode and effects analysis (FMEA), for instance, widely used for decades in automotive engineering, was recently targeted by the president of the JCAHCO in the US as a critical tool for enhancing safety. ${ }^{6}$ There are also quantitative candidates from the industrial "error management tool box" ranging from the nuclear power probabilistic risk assessment (PRA) to the HEART techniques. Retrospective approaches are used to describe and analyse actual incidents into their root causes and have been around much longer. Reason's error model $^{2}$ is the basis of a number of medical incident analysis tools. ${ }^{7}$

Finally, reports from the US Institute of Medicine ${ }^{8}$ and the UK Department of
Health ${ }^{9}$ underscored the essential mechanisms for organisational learning and the value of event and "near miss" reporting mechanisms. ${ }^{10}$ These tools allow large databases to be created quickly, but also are instruments to change the medical culture by involving and relying upon all levels of staff to provide input by (voluntary) sharing of experiences at the "sharp end". These reporting systems depend on trust by the frontline workers and make them a potentially powerful driving force towards achieving a "just culture". ${ }^{11}$

\section{CHALLENGING DIFFERENCES}

Healthcare tasks and contexts differ from industry and transportation in a number of important ways which should lead to appropriate adjustments of the safety management tools and techniques.

Perhaps the most striking difference is the highly dynamic nature and lack of standardisation in health care. ${ }^{12}$ At any given time it is not always clear what the proper actions are and-even more sothe change over time and contexts. Physicians pride themselves in practising the art of medicine and are reluctant to follow accepted guidelines, leading to large variation in practice. If this is true, it is rather disconcerting that the medical community looks predominantly to the solutions developed by a domain which is possibly at the very other end of this scale-namely, civil aviation. Aviation owes its major safety leaps forward mainly to the very rigid and consistent standardisation of its technology, tasks, procedures, and personnel. A unique feature of healthcare safety is that the patients themselves are key players, not only as the object of protection but also as an additional source of error. At times patients are contributors to error, but also can help with the timely detection of errors-for instance, when the medication or treatment they get differs from that which they expected. ${ }^{13}$

It remains to be seen how useful tools and techniques developed with a focus on identifying, analysing, and preventing errors by individuals are in health care where the bulk of patient care is given by teams. We have much to learn from other domains in which the importance of team awareness and training is foreign to most healthcare workers. These differences, however, may be used to persuade safety researchers and practitioners to take an active interest in patient safety problems and solutions. Such a "winwin" situation for both the medical and non-medical community could overcome the traditional barriers to cooperation, thereby boosting patient safety by the rapid deployment of proven solutions that can be applied today.

Qual Saf Health Care 2002;1 1:205-206 
Correspondence to: Dr T W van der Schaaf, Associate Professor of Human Factors in Risk Control, Eindhoven University of Technology, Safety Management Group, PAV U-8, P O Box 513,5600 MB Eindhoven, The Netherlands; t.w.v.d.schaaf@tm.tue.nl

\section{REFERENCES}

1 Bogner MS. Human error in medicine. Hillside, NJ: Lawrence Erlbaum Association, 1994.

2 Reason JT. Managing the risks of organisational accidents. Aldershot, UK: Ashgate, 1997.

3 Van der Schaaf TW, Lucas DA, Hale AR eds. Near miss reporting as a safety tool. Oxford: Butterworth-Heinemann, 1991.
4 Woods DD, Cook RI. Nine steps to move forward from error. Cognition Technol Work 2002;4:137-44.

5 Carroll JS, Rudolph JW, Hatakenaka S. Root cause analysis as a cultural change at a chemical plant. Qual Saf Health Care 2002;11:000-0.

6 O'Leary DS. Testimony by the President of JCAHCO to the Committee on Energy and Commerce, Subcommittee on Health, Washington DC, 8 May 2002.

7 Vincent C, Taylor-Adams SE, Stanhope N. A framework for the analysis of risk and safety in medicine. BM 1998;316:1154-7.

8 Kohn LT, Corrigan JM Donaldson MS, eds. To err is human: building a safer health system. Washington DC: National Academy Press, 1999
9 Department of Health. An organisation with a memory. London: Stationery Office, 2000 (available at www.doh.gov.uk/ orgmemreport/index.htm)

10 Barach P, Small SD. Reporting and preventing medical mishaps: lessons from non-medical near miss reporting systems. BM 2000;320:759-63.

11 Marx D. Patient safety and the "just culture": a primer for health care executives. Report prepared for MERS-TM, Columbia University NYC, 17 April 2001

12 Amalberti R, Auroy Y. Modelling care drifts and safety conflicts in patient safety strategies. Qual Saf Health Care 2002 (submitted).

13 Barber N. Ensuring patients' satisfaction with information about their medicines. Qual Health Care $2001 ; 10: 130-1$

\section{Breaking bad news}

\section{L Millenson}

\section{Effective public accountability in health care demands effective communication to the public.}

The public release of healthcare performance information can easily turn into a media circus focusing on boondoggles and body counts. Michael Millenson, a former reporter with the Chicago Tribune who went on to become a health services researcher and author, reflects on the minor media storm that accompanied release of a study by the UK's National Patient Safety Agency (NPSA).

Releasing public information on medical errors is a delicate task. Context-or, more cynically, what modern public relations practitioners would call "spin" - is critical. At one extreme there is the "bad is good" approach of The Doctor's Dream, in which the 19th century British physician William Snowden Battles gave this tongue-in-cheek confession of his shortcomings:

\section{And thus I dreamt that round me stood The victims of disease \\ The patients I had failed to cure \\ Though some had paid my fees. \\ One said, "It is a happy place, \\ My bliss is unalloyed; \\ Through your mistakes just ten years more Of heaven I have enjoyed".}

At the other extreme is the minor media storm surrounding a study by the UK's National Patient Safety Agency (NPSA) of the feasibility of a "blame free" national incident reporting system. The agency was established in July 2001 to identify adverse events and "near misses" occurring in the National Health Service (NHS) and then to use that knowledge to improve safety. Its 9 month pilot involved 28 trusts across England and Wales. ${ }^{1}$

In June Health Secretary Alan Milburn was accused by political opponents and some in the press of trying to "suppress shocking figures" about the "true scale of NHS blunders". ${ }^{2}$ His transgression was allegedly refusing to release pilot study results that the government believed underestimated the extent of errors. Logically, this meant the government stood accused of not releasing information that, if the government had trumpeted it as accurate, would make the Department of Health look good (that is, few mistakes). Nonetheless, the hubbub caused the Department of Health to look defensive as it released the study at a press conference held the next day by Professor Liam Donaldson, England's Chief Medical Officer.

It is tempting to see this contretemps as confirmation that public discussion of errors promotes vilification rather than improvement. A more useful course, however, would be to acknowledge that public accountability is here to stay, and then to examine what can be learned from this and similar experiences.

\section{ROLE OF THE NEWS MEDIA}

The most important lesson is that the role of the news media is to tell stories. Those print and broadcast journalists whose stock in trade is sensationalism will inevitably sensationalize, whether deploring medical mistakes or glorifying miracle cures. Most journalists, though, are simply trying to "get it right" despite limited knowledge, limited time to produce a story, and even more limited time or space for the final product. Indeed, despite these obstacles, the media have played a helpful role in health care data releases ranging from a comprehensive survey of patient opinion on hospital care in California (personal communication, Ann Monroe, California HealthCare Foundation, 17 March 2002) to the annual release of clinical indicators on hospitals in Scotland. In the latter case, a local newspaper's charts presented the information in a more usable and patient friendly manner than the official version from the NHS (personal communication, Steve Kendrick, Information and Statistics Division, NHS in Scotland, 18 March 2002).

Similarly, when the US Medicare program released hospital mortality statistics during the late 1980 s and early 1990s, major newspapers did a better job of presenting the information than the government. One reason may have been that federal officials feared incurring the wrath of powerful physician and hospital groups by making it easy for the public to spot providers with low scores. That leads to a second important point.

\section{PUBLIC INFORMATION IS, INEVITABLY, POLITICAL INFORMATION}

Information important enough for the public to care about is important enough to generate a political response. In a system such as Britain's, the government is an easy target. However, even in a private system like that of the United States, the massive publicity given to a 1999 report estimating 48 000-98000 annual preventable hospital deaths from medical errors quickly generated hearings and proposed legislation both in Congress and in state legislatures.

In the case of the NPSA study, the government answered a political attack with a scientific discussion of data reliability. It should have pointed out the illogic of a cover-up of data that made the government look good (one tenth the 
error rate of international studies) or the sleaziness of a newspaper attack that relied on unnamed sources (as the initial story did). In the end, the government countered charges of perfidy by providing proof, as one newspaper put it, that "Britain's first attempt to measure the number of errors made in NHS hospitals was almost a complete failure". ${ }^{3}$ Speaking to reporters, Donaldson acknowledged that the study's conclusion that less than $1 \%$ of patients suffered an adverse incident was unreliable due to an overcomplicated reporting form and various computer problems. When those were fixed, the true level of errors would probably soar to $10 \%{ }^{1}$

In the US the Agency for Health Care Policy and Research (AHCPR) rudely learned the importance of political preparedness after releasing a guideline on lower back pain in adults that outraged orthopedic surgeons with its critical stance toward surgery. Congressional allies of the surgeons slashed the AHCPR funding in 1995 and almost killed the agency altogether. The AHCPR responded by dropping guideline production, mending political fences, and eventually changing its name to the Agency for Healthcare Research and Quality. This highlights a final point.

\section{DATA POWERFUL ENOUGH TO CAUSE CHANGE ARE INHERENTLY DISRUPTIVE}

Quality and safety problems have deep roots. Those who feel that either their wallets or their way of life is threatened will not go quietly-witness the "quality heroes and martyrs" stories featured regularly in this publication. ${ }^{45}$ Distortions and half truths are standard tools of status quo protection. For example, health insurer sponsored TV commercials featuring a putative everyday couple named Harry and Louise talking to each other at the kitchen table are widely credited with helping to fatally undermine President Bill Clinton's health reform proposals.

Ultimately, though, the problem is not the media messengers but the message. The Doctor's Dream notwithstanding, patients are unlikely to welcome an early entry through the pearly gates. Any public discussion of medical mistakes is bound to be complex, political and disruptive. Yet the hard truth is that public scrutiny and even outrage over quality and safety problems has repeatedly proved essential to motivate health system change. In order to prevail against those who would undermine their efforts, advocates of medical accountability must learn to couple their efforts on behalf of the public with effective communication directly to that public through the news media.

Qual Saf Health Care 2002;11:206-207

Correspondence to: M L Millenson, Health Industry Management Program, Kellogg School of Management, Northwestern University, Donald P Jacobs Center, 2001 Sheridan Road Evanston, Illinois 60208-2001, USA; m-millenson@northwestern.edu

\section{REFERENCES}

1 Vass A. Patient safety agency admits problems with its pilot scheme. BMJ 2002:324: 1473 .

2 Maresh B, Hughes D. And now: the great hospital blunders cover-up. Daily Mail 18 June 2002, section 1, 1: 4 .

3 Hawkes, N. NHS attempt to measure errors ends in failure. The Times 19 June 2002 (NB page not available online).

4 Neuhauser D. Ernest Amory Codman MD. Qual Saf Health Care 2002; 11:104-5.

5 Neuhauser D, Harper DL. Too good to last: did Cleveland Health Quality Choice leave a legacy and lessons to be learned? Qual Saf Health Care 2002;11:202-3.

6 Millenson ML. Pushing the profession: how the news media turned patient safety into a priority. Qual Saf Health Care 2002;11:57-63. 